University of Nebraska - Lincoln

DigitalCommons@University of Nebraska - Lincoln

2008

\title{
Advective Removal of Intraparticle Uranium from Contaminated Vadose Zone Sediments, Hanford, U.S.
}

\author{
Eugene Ilton \\ Pacific Northwest National Laboratory, Eugene.Ilton@pnl.gov \\ Nikolla P. Qafoku \\ Pacific Northwest National Laboratory, nik.qafoku@pnl.gov \\ Chongxuan Liu \\ Pacific Northwest National Laboratory, chongxuan.liu@pnl.gov \\ Dean Moore \\ Pacific Northwest National Laboratory \\ John M. Zachara \\ Pacific Northwest National Laboratory, john.zachara@pnl.gov
}

Follow this and additional works at: https://digitalcommons.unl.edu/usdoepub

Part of the Bioresource and Agricultural Engineering Commons

Ilton, Eugene; Qafoku, Nikolla P.; Liu, Chongxuan; Moore, Dean; and Zachara, John M., "Advective Removal of Intraparticle Uranium from Contaminated Vadose Zone Sediments, Hanford, U.S." (2008). US Department of Energy Publications. 236.

https://digitalcommons.unl.edu/usdoepub/236

This Article is brought to you for free and open access by the U.S. Department of Energy at DigitalCommons@University of Nebraska - Lincoln. It has been accepted for inclusion in US Department of Energy Publications by an authorized administrator of DigitalCommons@University of Nebraska - Lincoln. 
Advective Removal of Intraparticle Uranium from Contaminated Vadose Zone Sediments, Hanford, U.S.

\author{
E U GENE S. ILTON, * \\ NIKOLLA P. QAFOKU, CHONGXUAN LIU, \\ DEAN A. MOORE, AND \\ J O H M. Z A C H A A. \\ Pacific Northwest National Laboratory, Chemical Science \\ Division, 902 Battelle Boulevard, MS: K8-96, \\ Richland, Washington 99352
}

Received May 11, 2007. Revised manuscript received September 7, 2007. Accepted September 13, 2007.

A column study on U(VI)-contaminated vadose zone sediments from the Hanford Site, WA, was performed to investigate $\mathrm{U}(\mathrm{VI})$ release kinetics with water advection and variable geochemical conditions. The sediments were collected from an area adjacent to and below tank BX-102 that was contaminated as a result of a radioactive tank waste overfill event. The primary reservoir for $\mathrm{U}(\mathrm{VI})$ in the sediments are micrometersize precipitates composed of nanocrystallite aggregates of a NaU-Silicate phase, most likely Na-boltwoodite, that nucleated and grew within microfractures of the plagioclase component of sand-sized granitic clasts. Two sediment samples, with different $\mathrm{U}(\mathrm{VI})$ concentrations and intraparticle mass transfer properties, were leached with advective flows of three different solutions. The influent solutions were all calcite-saturated and in equilibrium with atmospheric $\mathrm{CO}_{2}$. One solution was prepared from DI water, the second was a synthetic groundwater (SGW) with elevated $\mathrm{Na}$ that mimicked groundwater at the Hanford site, and the third was the same SGW but with both elevated $\mathrm{Na}$ and $\mathrm{Si}$. The latter two solutions were employed, in part, to test the effect of saturation state on $\mathrm{U}(\mathrm{VI})$ release. For both sediments, and all three electrolytes, there was an initial rapid release of $\mathrm{U}(\mathrm{VI})$ to the advecting solution followed by slower near steady-state release. U(VI)aq concentrations increased during subsequent stop-flow events. The electrolytes with elevated $\mathrm{Na}$ and Si depressed U(VI)aq concentrations in effluent solutions. Effluent $\mathrm{U}(\mathrm{VI})$ aq concentrations for both sediments and all three electrolytes were simulated reasonably well by a three domain model (the advecting fluid, fractures, and matrix) that coupled $\mathrm{U}(\mathrm{VI})$ dissolution, intraparticle $\mathrm{U}(\mathrm{VI})$ aq diffusion, and interparticle advection, where diffusion and dissolution properties were parameterized in a previous batch study.

\section{Introduction}

Uranium is a ubiquitous environmental contaminant with multiple sources such as mining, isotopic enrichment processes, and milling (1). At the U.S. Department of Energy's Hanford site, highly radioactive reprocessing waste was stored in clusters of buried tanks called "tank farms". In 1951, a massive leak within the BX tank farm (tank BX-102) occurred,

\footnotetext{
* Corresponding author phone: (509)-376-5022; e-mail: Eugene.Ilton@pnl.gov.
}

resulting in a uranium plume $250 \mathrm{~m}$ wide and $900 \mathrm{~m}$ long $(2,3)$ in vadose-zone sediments beneath the tank. Characterization of the contaminated sediments with various microscopic and spectroscopic approaches (4-6) indicated that uranium was hexavalent and occurred as micron-sized uranyl silicate crystallites that grew exclusively within plagioclase microfractures in sand-sized granitic clasts. These precipitates formed beautiful floret morphologies (Figure 1), with compositions and solubility that most closely matched Na-boltwoodite $(7,8)$. A previous batch study (8) found that $\mathrm{U}$ release from the sediments was kinetically controlled, and a model that coupled kinetic dissolution of Na-boltwoodite and uranyl diffusion in microfractures was required to simulate the slow observed release of $U(V I)$ to the aqueous phase. The model consists of fast and slow diffusion domains that were conceptualized as an interconnected network of relatively large and small fractures where uranyl dissolves and diffuses. A recent study that used nuclear magnetic resonance (NMR), pulse gradient spin-echo (PGSE) measurements confirmed the presence of both fast and slow intraparticle diffusion domains within the granitic clasts of the sediments (9).

Other studies have observed kinetically controlled release of $\mathrm{U}(\mathrm{VI})$ from nonuranyl mineral structures and surfaces (10-12), and from contaminated sediments (13-15). Such behavior was also attributed to diffusion, mass transfer, and/ or chemical kinetics. However, in all these studies, uranyl release was modeled with empirical rate expressions that did not account for microscopic processes or sediment heterogeneity. In contrast, the batch study (8), described above, provided insights into the microscopic mechanisms and heterogeneous pathways for U(VI) release from Hanford sediments. Nonetheless, the insights gained and kinetic parameter values derived from the batch study were likely compromised to some degree by the unavoidable convolution of $U(V I)$ dissolution kinetics and intragrain diffusion with saturation state as uranyl accumulated in the bulk solution. Given the complex kinetics that result from the intimate coupling of diffusion and dissolution, a more dynamic experiment is required to better understand this system, especially at later time stages when the batch experiments were not sensitive enough because of the mass action limitation, i.e., approach to equilibrium.

In this contribution, we have applied the conceptual model and the parameters derived from the batch experiments (8) to model column effluent data of $\mathrm{U}(\mathrm{VI})$ release from the same contaminated Hanford sediments with water advection that removed dissolution products. The experiments employed multiple stop-flow (SF) events of increasing duration, continuous leaching, and variable electrolytes. Different electrolytes were specifically targeted to suppress solubility, and thus dissolution kinetics. The dynamic hydraulic and different geochemical conditions produced variable $\mathrm{U}(\mathrm{VI})$ aq activity gradients between the bulk solution and sediment pores, which allowed for a more thorough study of the coupled diffusion and dissolution process. The information gained in this study constitutes an important step toward understanding $\mathrm{U}(\mathrm{VI})$ release and transport under relevant field conditions at Hanford, and other sites with precipitated $\mathrm{U}(\mathrm{VI})$.

\section{Materials and Methods}

Contaminated Sediments. The uranium contaminated sediments were collected by Rogers (16) from the vadose zone below and adjacent to tank BX-102 at the Hanford BX tank farm (Borehole 299-E33-45). Sediments 53AB and 61AB, 


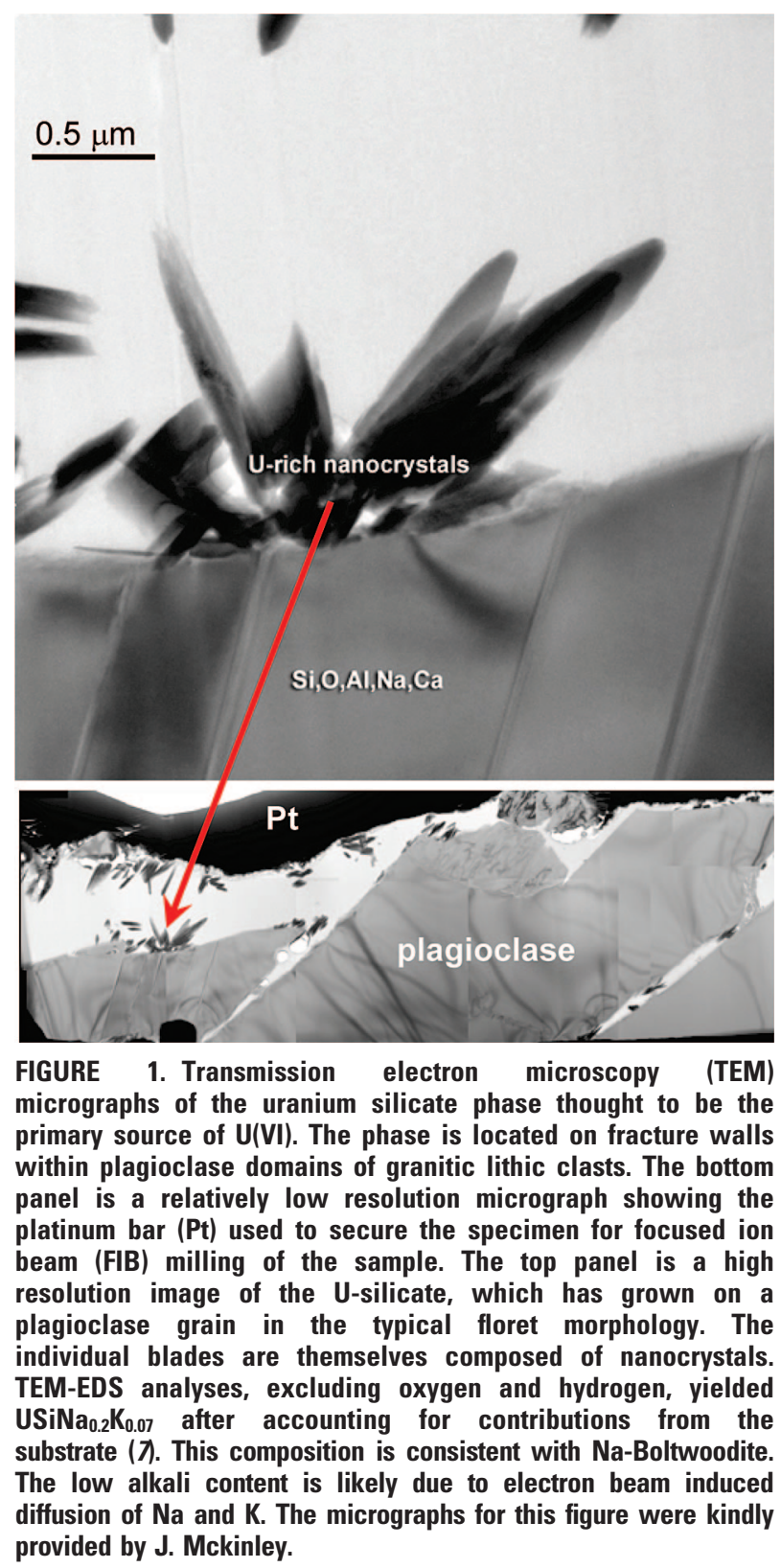

collected at depths of approximately 36 and $40 \mathrm{~m}$ below the surface, were used in the study. These sediments represent subsurface zones with some of the highest concentrations of uranium, where $U$ concentrations are 0.47 and $1.7 \mu \mathrm{mol} / \mathrm{g}$ in sediments $53 \mathrm{AB}$ and $61 \mathrm{AB}$, respectively. A schematic stratigraphic column showing the locations of these two sediments and the U concentration depth profile, detailed pore water compositions, mineralogy and down borehole physical parameters are available in ref $2,7,8$. The precipitated uranium is mainly associated with granitic clasts that comprise only about $4 \%$ of the sediment volume. Mass dominant basaltic lithic fragments do not appear to hold these precipitates. The mode of uranium emplacement in these clasts has been discussed in the Introduction and by McKinley et al. (7).

Electrolyte Preparation. Three different solutions were prepared (Table 1) that were in equilibrium with calcite and atmospheric $\mathrm{P}_{\mathrm{CO}_{2}}$ (bubbled with $\mathrm{H}_{2} \mathrm{O}$ saturated air for 1 week): (1) DI-water (Ca-DI); (2) Na-rich synthetic groundwater (SGW2-Na); (3) Si + Na-rich synthetic groundwater (SGW2$\mathrm{Na}+\mathrm{Si}$ ). $\mathrm{NaNO}_{3}$ was added to SGW2-Na and SGW2-Na + $\mathrm{Si}$ to bring the Na concentrations to $50 \mathrm{mM}$. To increase the $\mathrm{Si}$ concentration, SGW2-Na $+\mathrm{Si}$ was reacted with sodium

TABLE 1. Composition of the Simulated Groundwaters (SGW) Used in These Experiments ${ }^{a}$

Ca-DI $\mu$ M SGW2-Na $\mu$ M SGW2-Na + Si $\mu$ M

$\begin{array}{llll}\mathrm{Na} & \text { nd } & 44.8 \times 10^{3} & 49.2 \times 10^{3} \\ \mathrm{Ca} & 561.3 & 645.3 & 645.7 \\ \mathrm{Mg} & \text { nd } & 438.9 & 441.8 \\ \mathrm{~K} & \text { nd } & 495.9 & 466.0 \\ \mathrm{Si} & \text { nd } & \text { nd } & 747.3 \\ \mathrm{DIC}^{b}\left(\left[\mathrm{CO}_{3}\right]_{\text {TOT }}\right) & 1.10 \times 10^{3} & 1.24 \times 10^{3} & 1.03 \times 10^{3} \\ \mathrm{SO}_{4} & \text { na } & \text { na } & 921.5 \\ \mathrm{NO}_{3} & \text { na } & \text { na } & \text { na } \\ \mathrm{pH} & 8.26 & 8.16 & 8.20\end{array}$

${ }^{a}$ nd, not detected; na, not analyzed. Solutions were in equilibrium with calcite and ambient room atmosphere. ${ }^{b}$ DIC stands for dissolved inorganic carbon.

metasilicate. Calculations indicated that the electrolytes were under-saturated with respect to amorphous $\mathrm{SiO}_{2}$ (MINTEQ (17) with an updated database collected from literature).

Column Experiments. The columns were constructed of PVC with dimensions $2.4 \mathrm{~cm}$ (inner diameter) by $5.45 \mathrm{~cm}$ (length) and packed with the sediments in $10 \mathrm{~g}$ increments that were tamped by hand with a plastic dowel. Porous plates of $2.5 \mathrm{~mm}$ thickness with $10 \mu \mathrm{m}$ pores were placed at the top and bottom of each column to distribute the electrolyte evenly and to filter fines from the effluent. Spot compositional analyses of the effluent with and without additional $0.2 \mu \mathrm{m}$ filtration showed no detectable difference. The columns were held in the vertical position with the inlet at the bottom to promote hydraulic saturation. Solutions were injected with a 3M, 3000 modular infusion pump. Effluent samples (2-3 $\mathrm{mL}$ ) were collected with the ISSCO, Foxy Jr auto fraction sampler. The electrolyte reservoir was kept open to the atmosphere. A constant flow rate was applied during the initial saturation and leaching phases with a fluid residence time of approximately $1 \mathrm{~h}$, except during SF periods, when there was no advection, which ranged from 48 to $196 \mathrm{~h}$. $\mathrm{U}(\mathrm{VI}) \mathrm{aq}$ analyses were performed at $0.2,0.4,0.6,0.8,1.0,1.2$, 1.5 , and 2.0 pore volumes (PV), and thereafter at each $0.5 \mathrm{PV}$ increment. Frequent measurements of $\mathrm{pH}$ were taken, with particular emphasis on bracketing the SF events. Individual effluent samples were composited for analyses of all other solutes. Three composite samples were prepared from effluent samples collected in the first $20 \mathrm{PV}$ : the first composite sample represented the first $1 / 2 \mathrm{PV}$ of effluent, while the other two were collected at $\sim 5 \mathrm{PV}$ and $\sim 19 \mathrm{PV}$ (the latter was collected right before the first SF); Three composite samples were collected from 20 to $40 \mathrm{PV}$ : again, the first composite sample represented the first $1 / 2 \mathrm{PV}$ of effluent collected when flow was reestablished after the first SF event; the other two were collected at about $25 \mathrm{PV}$ (at the shoulder) and $39 \mathrm{PV}$ (at the plateau just before the second SF). The same sample collecting method and frequency were applied for all the SF events.

Effluent Analyses. Aqueous U concentrations were measured with a kinetic phosphorescent analyzer (Chemcheck Instruments Inc., Richland WA). The KPA analyses only measure U(VI)aq; however, any contribution from potential U(IV)aq that oxidized to U(VI)aq prior to analysis would have been trivial as discussed in the Results and Discussion section. Major cations ( $\mathrm{Si}, \mathrm{Ca}, \mathrm{Mg}, \mathrm{Na}, \mathrm{K}$ ) and $\mathrm{S}$ were analyzed with a Perkin-Elmer, optical emission spectrometer, Optima 2100DV; total dissolved inorganic carbon (DIC) was measured with a Dohrman carbon analyzer, DC-80; Br concentrations were obtained with a bromide, Accumet ION specific glass body electrode; $\mathrm{pH}$ was determined with a thermo ORION ROSS glass semimicro combination electrode. 
U(VI) desorption from sediment $53 \mathrm{AB}$
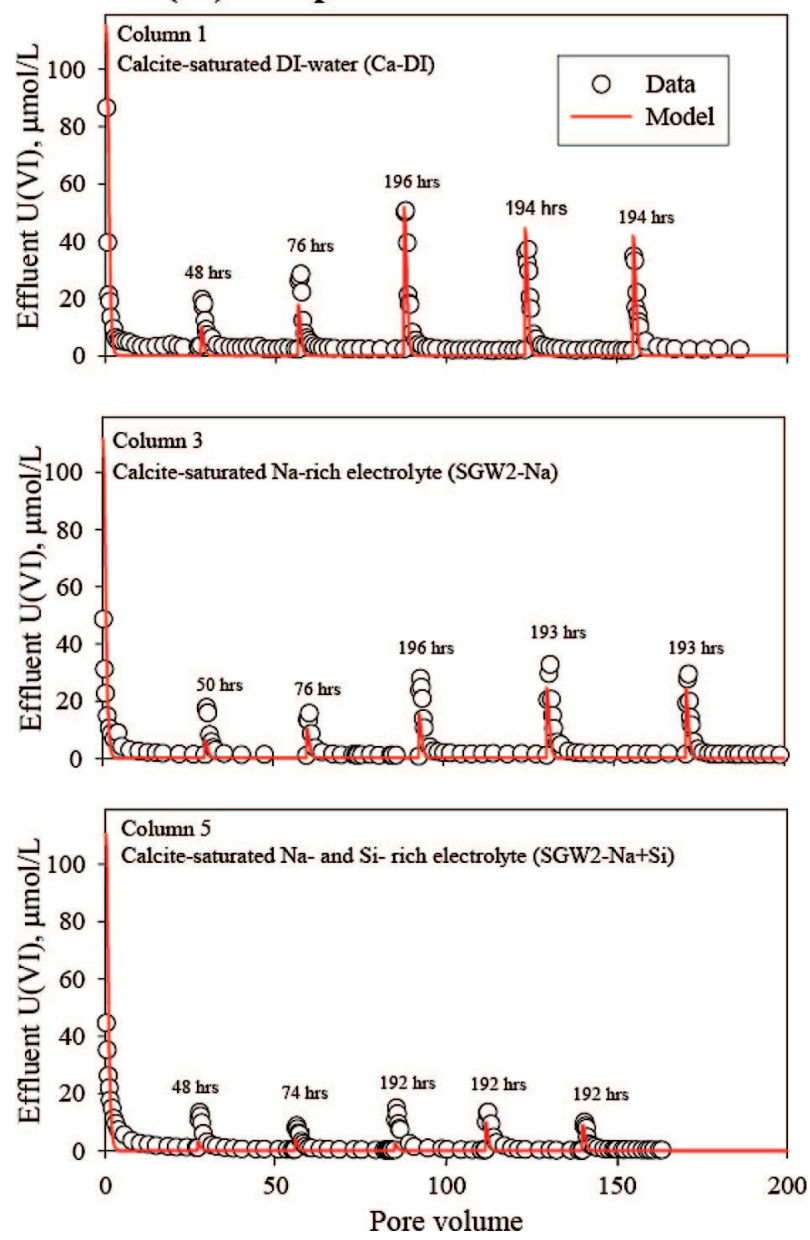

FIGURE 2. Effluent data for uranium release from sediment 53AB. The open circles represent the experimental data, the solid red line is the simulation. The time duration for each stop-flow event are given in hours. Top, middle, and bottom panels show results of leaching with the electrolytes Ca-DI, SGW2-Na, and SGW2-Na $+\mathrm{Si}$, respectively.

\section{Results and Discussion}

Evolution of Solution Compositions. For all six experiments, involving two sediments (53AB and 61AB) and three electrolytes (Table 1), effluent $\mathrm{U}(\mathrm{VI}) \mathrm{aq}$ reached its highest concentration within the first PV and then rapidly decreased with only slight changes after five pore volumes (Figures 2 and 3). This quasi steady state U(VI)aq concentration indicated that the rate of $\mathrm{U}(\mathrm{VI})$ release from the sediment to the aqueous phase was close to the rate of advective removal of $U(V I)$ from the column. The initial rapid release of $U(V I)$ was consistent with observations in the batch system (8) which showed that a small but labile fraction of sediment $\mathrm{U}(\mathrm{VI})$ was present as an adsorbed and/or soluble species. $\mathrm{U}(\mathrm{VI})$ aq concentrations strongly rebounded during the stopflow events clearly indicating that $\mathrm{U}(\mathrm{VI})$ release from the sediments was kinetically controlled. Upon recommencement of flow, U(VI)aq concentrations rapidly dropped over the course of $\sim 6 \mathrm{PV}$, and reached steady values by $\sim 10-18$ $\mathrm{PV}$. Aqueous $\mathrm{U}$ concentrations were $\sim 1.5$ to $\sim 3$ orders of magnitude higher than those predicted for U(IV)aq in equilibrium with $\mathrm{UO}_{2} \cdot \mathrm{nH}_{2} \mathrm{O}(\mathrm{am})$ (18). Consequently, $\mathrm{U}(\mathrm{VI}) \mathrm{aq}$ species were dominant despite the presence of reducing agents such as ferrous iron in the basaltic lithic clasts. This is consistent with Na-boltwoodite as the solubility controlling phase, as discussed below.

Effluent U(VI)aq and solute concentrations, and the saturation index for U(VI) are given in Table 2. For the Ca-DI
$\mathrm{U}(\mathrm{VI})$ desorption from sediment $61 \mathrm{AB}$
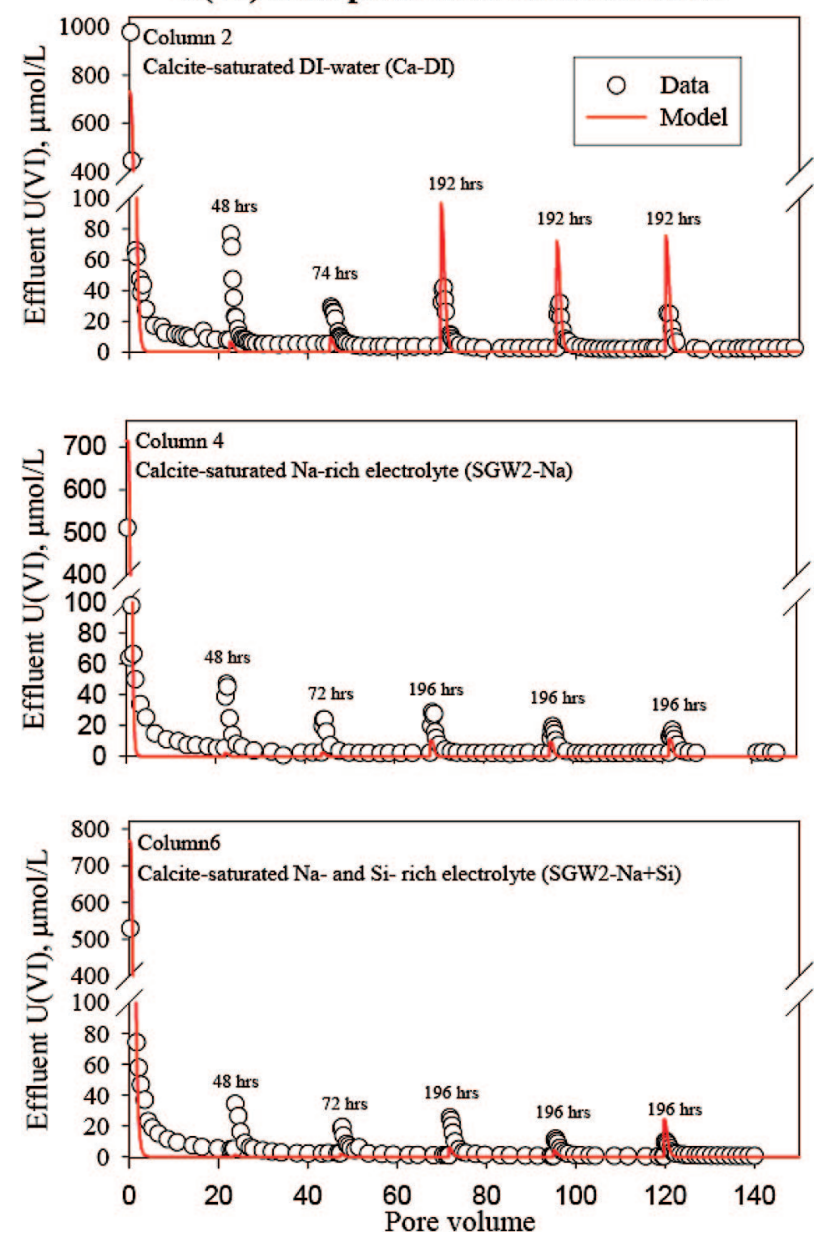

FIGURE 3. Effluent data for uranium release from sediment 61AB. The open circles represent the experimental data, the solid red line is the simulation. The time duration for each stop-flow event are given in hours. Top, middle, and bottom panels show results of leaching with the electrolytes Ca-DI, SGW2-Na, and SGW2-Na $+\mathrm{Si}$, respectively.

electrolyte, effluent U(VI)aq concentrations were consistently well under-saturated (Table 2) with respect to the calculated concentration of U(VI)aq in equilibrium with $\mathrm{Na}$-boltwoodite (Table 3) during the SF events and the flow regime, indicating that $U(V I)$ release was kinetically limited. The U solubility was calculated using the solute concentrations in Table 2 and the solubility constant for Na-boltwoodite $\left(\log K_{\mathrm{sp}}=6.08\right.$ \pm 0.5 ) that was determined in the batch system (8) for the reaction $\mathrm{Na}\left[\mathrm{UO}_{2}\left(\mathrm{SiO}_{3} \mathrm{OH}\right)\right]\left(\mathrm{H}_{2} \mathrm{O}\right)_{1.5}+3 \mathrm{H}^{+}=\mathrm{UO}_{2}{ }^{2+}+\mathrm{Na}^{+}+$ $\mathrm{H}_{4} \mathrm{SiO}_{4}+1.5 \mathrm{H}_{2} \mathrm{O}$ (See Modeling section for more details). The fast initial release of U(VI) was accompanied by fast releases of $\mathrm{Na}, \mathrm{K}$ (just sediment $53 \mathrm{AB}$ ), sulfate, carbonate, and $\mathrm{P}$ (just sediment $61 \mathrm{AB}$ ), which suggests that these elements also were present in the labile fraction (data not shown). This is consistent with the measured porewater compositions for these sediments (2). Most of the solutes, with the exception of $\mathrm{P}$, tended to rebound along with $\mathrm{U}(\mathrm{VI}) \mathrm{aq}$ during SF. P concentrations rapidly dropped below detection with time. Mg was not detected during the first 20 PVs (or during the first SF for sediment 61). This implies that Mg was not strongly associated with the labile fraction. In most cases the concentrations of $\mathrm{U}(\mathrm{VI}) \mathrm{aq}$ along with all other solutes except for $\mathrm{Ca}$, which was supplied by the input solution, decreased over the last three SF events of near equal duration; although the differences in U(VI)aq concentrations between the last two SF events were marginal. Except for column 1, the largest percentage drop in peak U(VI)aq concentrations 
TABLE 2. Effluent Compositions (umol/L) and U Saturation Index (SI) ${ }^{a}$

\begin{tabular}{|c|c|c|c|c|c|c|c|c|c|c|}
\hline & $\mathrm{Ca}$ & K & $\mathbf{M g}$ & $\mathrm{Na}$ & $\mathrm{SO}_{4}{ }^{2-}$ & $\mathrm{H}_{4} \mathrm{SiO}_{4}$ & $\mathbf{C}_{\mathrm{T}}$ & pH & U & ${ }^{c} \mathbf{S I}_{\mathbf{U}}$ \\
\hline \multicolumn{11}{|l|}{ col 1} \\
\hline SF1 & 328.59 & 150.72 & 138.20 & 894.09 & 50.31 & 272.38 & $1.53 \times 10^{3}$ & 8.19 & 19.8 & -0.602 \\
\hline SF2 & 515.47 & 226.35 & 202.63 & 167.16 & 30.13 & 197.93 & $1.53 \times 10^{3}$ & 8.19 & 28.6 & -1.448 \\
\hline SF3 & 724.68 & 358.08 & 181.28 & 131.10 & 36.81 & 207.98 & $1.81 \times 10^{3}$ & 8.22 & 50.7 & -1.297 \\
\hline SF4 & 683.88 & 323.93 & 93.15 & 75.47 & 25.70 & 165.81 & $1.58 \times 10^{3}$ & 8.19 & 37.2 & -1.758 \\
\hline SF5 & 661.18 & 95.07 & 59.45 & 48.28 & 22.18 & 144.52 & $1.51 \times 10^{3}$ & 8.27 & 34.9 & -1.860 \\
\hline $\begin{array}{l}\text { flow }^{b} \\
\text { col } 2\end{array}$ & 511.81 & 231.13 & 79.76 & 31.35 & 15.60 & 61.70 & $1.27 \times 10^{3}$ & 8.23 & 2.4 & -3.204 \\
\hline SF1 & 34.76 & 55.91 & $<20.57$ & $2.69 \times 10^{3}$ & 69.40 & 267.07 & $2.99 \times 10^{3}$ & 9.46 & 76.7 & 0.077 \\
\hline SF2 & 291.54 & 225.33 & 32.50 & $1.10 \times 10^{3}$ & 55.55 & 189.67 & $1.77 \times 10^{3}$ & 8.35 & 29.5 & -0.480 \\
\hline SF3 & 695.73 & 218.43 & 71.55 & 474.73 & 75.39 & 199.01 & $1.97 \times 10^{3}$ & 8.08 & 42.1 & -1.993 \\
\hline SF4 & 766.72 & 158.30 & 63.90 & 229.10 & 52.43 & 165.03 & $1.92 \times 10^{3}$ & 8.06 & 32.1 & -1.562 \\
\hline SF5 & 736.15 & 121.59 & 49.41 & 120.84 & 34.56 & 135.62 & $1.80 \times 10^{3}$ & 8.18 & 25.4 & -1.883 \\
\hline $\begin{array}{l}\text { flow }^{b} \\
\text { col } 3\end{array}$ & 503.90 & 63.12 & 33.30 & 49.29 & 1.56 & 63.82 & $1.27 \times 10^{3}$ & 8.25 & 3.5 & -2.881 \\
\hline SF1 & 859.53 & $1.87 \times 10^{3}$ & 534.25 & $40.27 \times 10^{3}$ & $1.00 \times 10^{3}$ & 222.67 & $1.96 \times 10^{3}$ & 8.41 & 17.8 & 0.157 \\
\hline SF2 & 691.44 & $1.59 \times 10^{3}$ & 474.51 & $45.24 \times 10^{3}$ & 974.36 & 170.26 & $2.16 \times 10^{3}$ & 8.68 & 15.8 & -0.021 \\
\hline SF3 & 621.26 & 993.53 & 507.92 & $46.59 \times 10^{3}$ & 957.11 & 155.77 & $2.30 \times 10^{3}$ & 9.22 & 28.0 & 0.219 \\
\hline SF4 & 780.39 & 921.74 & 487.35 & $45.15 \times 10^{3}$ & 890.61 & 131.48 & $2.48 \times 10^{3}$ & 9.06 & 32.8 & 0.046 \\
\hline SF5 & 743.71 & $1.16 \times 10^{3}$ & 499.69 & $43.89 \times 10^{3}$ & 867.37 & 102.22 & $2.39 \times 10^{3}$ & 9.29 & 29.5 & -0.004 \\
\hline $\begin{array}{l}\text { flow }^{b} \\
\text { col } 4\end{array}$ & 699.48 & 873.74 & 464.11 & $44.78 \times 10^{3}$ & 911.79 & 17.80 & $1.55 \times 10^{3}$ & 8.28 & 1.2 & -1.631 \\
\hline SF1 & 439.82 & 594.28 & 306.69 & $45.54 \times 10^{3}$ & $1.05 \times 10^{3}$ & 256 & $2.22 \times 10^{3}$ & 8.87 & 47.0 & 0.673 \\
\hline SF2 & 684.13 & 684.69 & 473.36 & $44.67 \times 10^{3}$ & 869.00 & 383.64 & $2.07 \times 10^{3}$ & 8.55 & 24.0 & 0.543 \\
\hline SF3 & 709.91 & 681.49 & 486.44 & $44.28 \times 10^{3}$ & 959.45 & 171.72 & $2.38 \times 10^{3}$ & 8.69 & 19.5 & -0.052 \\
\hline SF4 & 655.89 & 632.85 & 486.85 & $45.19 \times 10^{3}$ & 981.75 & 140.14 & $2.19 \times 10^{3}$ & 8.65 & 28.7 & 0.155 \\
\hline SF5 & 791.12 & 986.19 & 495.49 & $47.01 \times 10^{3}$ & $1.05 \times 10^{3}$ & 121.13 & $2.31 \times 10^{3}$ & 8.97 & 17.1 & -0.187 \\
\hline $\begin{array}{l}\text { flow }^{b} \\
\text { col } 5\end{array}$ & 696.63 & 653.36 & 477.97 & $46.22 \times 10^{3}$ & 953.99 & 42.89 & $1.56 \times 10^{3}$ & 8.51 & 2.4 & -0.993 \\
\hline SF1 & 828.78 & 868.97 & 560.17 & $44.41 \times 10^{3}$ & $1.03 \times 10^{3}$ & 705.44 & $2.08 \times 10^{3}$ & 8.61 & 13.5 & 0.503 \\
\hline SF2 & 806.45 & $3.00 \times 10^{3}$ & 521.21 & $42.57 \times 10^{3}$ & $1.02 \times 10^{3}$ & 25 & $2.11 \times 10^{3}$ & 8.52 & 8.8 & 0.281 \\
\hline SF3 & 775.01 & 661.29 & 509.12 & $44.15 \times 10^{3}$ & 976.14 & 729.12 & $1.77 \times 10^{3}$ & 8.63 & 15.0 & 0.787 \\
\hline SF4 & 829.65 & $1.18 \times 10^{3}$ & 539.11 & $42.81 \times 10^{3}$ & $1.00 \times 10^{3}$ & 723.42 & $2.75 \times 10^{3}$ & 8.11 & 13.6 & 0.129 \\
\hline SF5 & 675.90 & 791.34 & 422.96 & $45.16 \times 10^{3}$ & 895.20 & 661.18 & $2.71 \times 10^{3}$ & 8.28 & 10.1 & 0.049 \\
\hline $\begin{array}{l}\text { flow }^{b} \\
\text { col } 6\end{array}$ & 759.93 & 674.17 & 484.43 & $45.15 \times 10^{3}$ & 915.80 & 746.04 & $1.66 \times 10^{3}$ & 8.20 & 0.35 & -0.763 \\
\hline SF1 & 463.27 & 608.04 & 340.92 & $42.66 \times 10^{3}$ & $1.03 \times 10^{3}$ & 660.47 & $2.03 \times 10^{3}$ & 8.61 & 34.4 & 1.010 \\
\hline SF2 & 661.75 & 822.17 & 467.39 & $44.37 \times 10^{3}$ & $1.02 \times 10^{3}$ & 688.96 & $2.15 \times 10^{3}$ & 8.76 & 19.3 & 0.669 \\
\hline SF3 & 754.49 & 874.98 & 523.55 & $43.89 \times 10^{3}$ & 977.01 & 658.51 & $2.58 \times 10^{3}$ & 8.52 & 25.6 & 0.491 \\
\hline SF4 & 732.53 & 797.48 & 505.66 & $46.28 \times 10^{3}$ & 975.05 & 698.57 & $2.40 \times 10^{3}$ & 8.19 & 11.8 & 0.282 \\
\hline SF5 & 692.12 & 744.03 & 403.66 & $52.94 \times 10^{3}$ & 885.53 & & $5.01 \times 10^{3}$ & 8.30 & 10.1 & -0.696 \\
\hline flow $^{b}$ & 710.67 & 681.66 & 480.40 & $46.17 \times 10^{3}$ & 962.19 & 756.95 & $1.70 \times 10^{3}$ & 8.30 & 0.61 & -0.522 \\
\hline
\end{tabular}

${ }^{a}$ Columns 1, 3, and 5 used sediment $53 \mathrm{AB}$ and electrolytes Ca-DI, SGW2-Na, and SGW2-Na + Si, respectively. Columns 2,4 , and 6 used sediment $61 \mathrm{AB}$ and electrolytes $\mathrm{Ca}-\mathrm{DI}, \mathrm{SGW} 2-\mathrm{Na}$, and SGW2-Na $+\mathrm{Si}$, respectively. ${ }^{b}$ An average of inter stop-flow effluent compositions were used to calculate $U$ solubility between stop-flow events. Note that the common metals $\mathrm{Al}$ and Fe were consistently below detection. ${ }^{c}$ The mineral saturation index $\left(\mathrm{SI}_{u}\right)$ was approximated by log $\left[\mathrm{U}_{\mathrm{aq}} / \mathrm{U}_{\mathrm{eq}}\right]$, where $U_{\text {aq }}$ is the measured aqueous concentration of $U(\mathrm{VI})$ and $U_{\text {eq }}$ is the calculated aqueous concentration of $U(V I)$ that would be in equilibrium with Na-boltwoodite.

occurred between SF1 (48 h) and SF2 (76 h), despite SF2 having longer durations. This was accentuated for sediment $61 \mathrm{AB}$, which suggests that this behavior recorded depletion of $U$ from fast diffusion zones, where sediment $61 \mathrm{AB}$ contained a larger fraction of $U$ in slow diffusion domains than sediment $53 \mathrm{AB}(8)$.

For electrolytes SGW2-Na and SGW2-Na $+\mathrm{Si}$, the addition of $\mathrm{Na}$ and $\mathrm{Na}+\mathrm{Si}$ fixed these ions at constant concentrations (Table 2), which suppressed U(VI)aq during both flow and SF conditions (Table 2; Figures 2 and 3), despite an associated higher total carbonate concentration $\left(C_{T}\right)$ relative to the Ca-DI column experiments. SGW2-Na + Si suppressed U(VI)aq more than SGW2-Na. This was in accord with the microscopic evidence for Na-boltwoodite being the major reservoir for $\mathrm{U}$ in the sediments (see Introduction and Figure 1). In fact, effluent U(VI)aq was consistently near saturation (Table 2), given an uncertainty in $\log K_{\mathrm{sp}}= \pm 0.5$, for the SF events relative to the calculated solubility of Na-boltwoodite (Table 3). This suggested that $U(V I)$ release was solubility controlled (in contrast to the Ca-DI electrolyte). These two electrolytes (Table 1) contained initially elevated concentrations of all the solutes listed in Table 2, with the exception of Si for SGW2-Na. Accordingly, solute concentrations were fairly constant over the duration of the experiments and when transitioning from flow to SF conditions. For SGW2-Na, Si behaved as in the Ca-DI experiments described previously. Peak U(VI)aq concentrations recorded during the last three SF events for the SGW2-Na experiments did not decrease systematically, whereas peak U(VI)aq concentrations declined over the last three SF events for the SGW2-Na $+\mathrm{Si}$ experiments, similarly to the Ca-DI experiments. As discussed below, not much total U(VI) was leached, regardless of the sediment and electrolyte. Consequently, the abundance and distribution of $U(V I)$ in the sediments might not have been sufficiently altered to consistently influence the time evolution of the later SF events.

More U was released, both initially and integrated over time, from sediment $61 \mathrm{AB}$ relative to sediment $53 \mathrm{AB}$. This was consistent with sediment $61 \mathrm{AB}$ containing higher total $U$ as well as higher initial $U$ in the labile component compared to sediment $53 \mathrm{AB}$ (Table 2). In contrast, more $\mathrm{U}$ tended to be released from $53 \mathrm{AB}$ than $61 \mathrm{AB}$ during later 
TABLE 3. Parameters and Compositions Used in Modeling BX102 Sediment Effluent Data

column physical parameters

\begin{tabular}{|c|c|c|c|c|c|c|c|}
\hline columna & $L(\mathrm{~cm})$ & area $\left(\mathrm{cm}^{2}\right)$ & $\theta$ & $b_{\mathrm{v}}(\mathrm{cm} / \mathrm{h})$ & $\rho_{\mathrm{b}}\left(\mathrm{g} / \mathrm{cm}^{3}\right)$ & $\rho_{\mathrm{s}}\left(\mathrm{g} / \mathrm{cm}^{3}\right)$ & ${ }^{b} \mathrm{D}\left(\mathrm{cm}^{2} / \mathrm{h}\right.$ \\
\hline col 1 & 5.45 & 4.52 & 0.32 & 8.07 & 1.76 & 2.59 & 3.40 \\
\hline $\mathrm{col} 2$ & 5.45 & 4.52 & 0.41 & 6.25 & 1.77 & 3.00 & 3.10 \\
\hline $\mathrm{col} 3$ & 5.45 & 4.52 & 0.33 & 7.72 & 1.76 & 2.63 & 4.89 \\
\hline $\operatorname{col} 4$ & 5.45 & 4.52 & 0.42 & 6.00 & 1.77 & 3.05 & 1.81 \\
\hline col 5 & 5.45 & 4.52 & 0.34 & 7.48 & 1.79 & 2.71 & 7.34 \\
\hline $\operatorname{col} 6$ & 5.45 & 4.52 & 0.40 & 6.36 & 1.81 & 3.02 & 4.74 \\
\hline
\end{tabular}

\begin{tabular}{cccccc}
\multicolumn{5}{c}{ diffusion and kinetic parameters } \\
\hline sediment & $\mathbf{f 1}(\%)$ & $\mathbf{f 2}(\%)$ & $\mathbf{D}_{\mathrm{f}} / \mathbf{L}^{\mathbf{2}}\left(\mathbf{h}^{-1}\right)$ & $\mathbf{k}_{\mathbf{m}}\left(\mathbf{h}^{-1}\right)$ & $\left.\boldsymbol{k}_{(\mathbf{M}} \mathbf{M}^{-1} \mathbf{h}^{-1}\right)$ \\
$53 \mathrm{AB}$ & $2.13 \times 10^{-3}$ & 5 & 6.8 & 0.0035 & 0.066 \\
$61 \mathrm{AB}$ & $1.44 \times 10^{-3}$ & 50 & 0.26 & 0.0035 & 0.066
\end{tabular}

initial $\mathrm{U}(\mathrm{VI}) c$

\begin{tabular}{ccccc}
\hline sediment & total $\mathbf{U ~ ( m o l} / \mathbf{g})$ & elabile fraction $(\mathbf{m o l} / \mathbf{g})$ & solid fraction $(\mathbf{m o l} / \mathbf{g})$ & influent $\mathbf{~}$ \\
$53 \mathrm{AB}$ & $4.7 \times 10^{-7}$ & $2.1 \times 10^{-8}$ & $4.5 \times 10^{-7}$ & 0 \\
$61 \mathrm{AB}$ & $1.7 \times 10^{-6}$ & $1.7 \times 10^{-7}$ & $1.5 \times 10^{-6}$ & 0
\end{tabular}

calculated equilibrium U(VI) solubility (mol/L) based on LogK $_{\mathrm{sp}}$ (Na-boltwoodite) $=$ 6.08c $^{c}$

\begin{tabular}{|c|c|c|c|c|c|c|}
\hline \multicolumn{7}{|c|}{ reaction stoichiometry: $\mathrm{Na}\left[\mathrm{UO}_{2}\left(\mathrm{SiO}_{3} \mathrm{OH}\right)\right]\left(\mathrm{H}_{2} \mathrm{O}\right)_{1.5}+3 \mathrm{H}^{+}=\mathrm{UO}_{2}{ }^{2+}+\mathrm{Na}^{+}+\mathrm{H}_{4} \mathrm{SiO}_{4}+1.5 \mathrm{H}_{2} \mathrm{O}$} \\
\hline stop-flow & Col 1 & Col 2 & Col 3 & Col 4 & Col 5 & Col 6 \\
\hline SF1 & $7.92 \times 10^{-5}$ & $6.43 \times 10^{-5}$ & $1.24 \times 10^{-5}$ & $9.98 \times 10^{-6}$ & $4.24 \times 10^{-6}$ & $3.36 \times 10^{-6}$ \\
\hline SF2 & $8.03 \times 10^{-4}$ & $8.90 \times 10^{-5}$ & $1.66 \times 10^{-5}$ & $6.87 \times 10^{-6}$ & $4.61 \times 10^{-6}$ & $4.14 \times 10^{-6}$ \\
\hline SF3 & $1.05 \times 10^{-3}$ & $4.14 \times 10^{-3}$ & $1.69 \times 10^{-5}$ & $2.20 \times 10^{-5}$ & $2.45 \times 10^{-6}$ & $8.26 \times 10^{-6}$ \\
\hline SF4 & $2.13 \times 10^{-3}$ & $1.17 \times 10^{-3}$ & $2.95 \times 10^{-5}$ & $2.01 \times 10^{-5}$ & $1.01 \times 10^{-5}$ & $6.17 \times 10^{-6}$ \\
\hline SF5 & $2.53 \times 10^{-3}$ & $1.94 \times 10^{-3}$ & $2.98 \times 10^{-5}$ & $2.63 \times 10^{-5}$ & $9.02 \times 10^{-6}$ & $5.01 \times 10^{-5}$ \\
\hline Flow $^{d}$ & $3.84 \times 10^{-3}$ & $2.66 \times 10^{-3}$ & $5.13 \times 10^{-5}$ & $2.36 \times 10^{-5}$ & $2.03 \times 10^{-6}$ & $2.03 \times 10^{-6}$ \\
\hline
\end{tabular}

${ }^{a}$ Columns 1,3 , and 5 used sediment $53 \mathrm{AB}$ and electrolytes $\mathrm{Ca}-\mathrm{DI}, \mathrm{SGW} 2-\mathrm{Na}$, and SGW2-Na + Si, respectively. Columns 2, 4, and 6 used sediment 61AB and electrolytes Ca-DI, SGW2-Na, and SGW2-Na + Si, respectively. Definitions for the parameters are given in the Modeling section in the text. ${ }^{b} \mathrm{Br}$ tracer curves (Figure SI-1 in the Supporting Information) provided input for calculations with the CXFIT code (21) to determine transport parameters in the advective aqueous domain. ${ }^{c}$ Parameters are from Liu et al. (8). ${ }^{d}$ An average of inter stop-flow effluent compositions were used to calculate $\mathrm{U}(\mathrm{VI})$ solubility between SF events. ${ }^{e}$ The labile fraction represents initial $\mathrm{U}(\mathrm{VI})$ in the remaining porewater, and as sorbed species and/or soluble salts.

SF events (compare columns 1-4). This was consistent with the modeling results of the earlier batch study (8) which indicated that $61 \mathrm{AB}$ contained a greater proportion of $U$ in mass transport limited domains compared to $53 \mathrm{AB}$. However, a relatively small amount of the total U(VI) was mobilized from each sediment, despite the passage of well over 100 pore volumes solution through the columns and hundreds of hours of SF conditions. For example, only about 14 and $21 \%$ of the total $U$ was released from sediments $53 \mathrm{AB}$ and $61 \mathrm{AB}$, respectively, at the conclusion of leaching with the Ca-DI electrolyte.

For all sediments and electrolytes, U(VI)aq effluent concentrations during the flow regime were consistently well undersaturated (Table 2) with respect to the calculated U(VI) solubility. This was expected, and was one of the desired effects of advection.

Modeling. The modeling effort in this paper closely follows that of Liu et al. (8) for the batch dissolution study of the BX-102 sediments. Here, the coupled diffusion and dissolution model of the fracture and matrix systems was linked with advection to simulate U(VI) release from the BX-102 sediments. As in the batch study, U(VI)aq was the only diffusible species in the model. All other aqueous species were measured (Table 2) and used as input in the model to constrain the dissolution of the intragrain U(VI) phase; the only reaction considered was the dissolution of Na-boltwoodite. All solubility calculations used the same database (19) and activity corrections (the Davies equation) as in the batch study (8).
The initial fast release of U(VI) was modeled with U(VI) in the labile fraction of the sediments (Table 3). This adequately accounted for the much higher U(VI)aq concentrations in initial effluent solutions for both sediments (Figures 2 and 3). The coupled advection-diffusion-dissolution model contained parameters with values given in Table 3. The governing equations for the aqueous and solid concentrations of $U(V I)$ for the different domains in the onedimensional column system are given by eqs $1-3$, and 4 and 5, respectively:

Advective domain (aqueous):

$$
\frac{\partial C_{\mathrm{a}}(x, t)}{\partial t}=D \frac{\partial^{2} C_{\mathrm{a}}(x, t)}{\partial x^{2}}-v \frac{\partial C_{\mathrm{a}}(x, t)}{\partial x}-\left.f_{1} \frac{D_{\mathrm{f}}}{L_{\mathrm{f}}^{2}} \frac{\partial C_{\mathrm{f}}(x, l, t)}{\partial l}\right|_{l=0}
$$

Fracture domain (aqueous):

$$
\begin{array}{r}
\frac{\partial C_{\mathrm{f}}(x, l, t)}{\partial t}=\frac{D_{\mathrm{f}}}{L_{\mathrm{f}}^{2}} \frac{\partial^{2} C_{\mathrm{f}}(x, l, t)}{\partial l^{2}}+r_{\mathrm{f}}(x, l, t)-f_{2} k_{\mathrm{m}}\left(C_{\mathrm{f}}(x, l, t)-\right. \\
\left.C_{m}(x, l, t)\right)
\end{array}
$$

Matrix domain (aqueous):

$$
\frac{\partial C_{\mathrm{m}}(x, l, t)}{\partial t}=r_{\mathrm{m}}(x, l, t)+k_{\mathrm{m}}\left(C_{\mathrm{f}}(x, l, t)-C_{\mathrm{m}}(x, l, t)\right)
$$

Fracture domain (solid):

$$
\frac{\left(1-\theta_{\mathrm{f}}\right) \rho_{\mathrm{s}}}{\theta_{\mathrm{f}}} \frac{\partial S_{\mathrm{f}}(x, l, t)}{\partial t}=-r_{\mathrm{f}}(x, l, t)
$$


Matrix domain (solid):

$$
\frac{\left(1-\theta_{\mathrm{m}}\right) \rho_{\mathrm{s}}}{\theta_{\mathrm{m}}} \frac{\partial S_{\mathrm{m}}(x, l, t)}{\partial t}=-r_{\mathrm{m}}(x, l, t)
$$

where $C_{\mathrm{a}}, C_{\mathrm{f}}$, and $C_{\mathrm{m}}$ are the concentrations (mol/L) of $\mathrm{U}(\mathrm{VI}) \mathrm{aq}$ in the aqueous phases associated with the advective, fracture, and matrix domains, respectively; $S_{\mathrm{f}}$ and $S_{\mathrm{m}}$ are the concentrations $(\mathrm{mol} / \mathrm{kg}$ ) of U(VI) in the solid fractions associated with the fracture and matrix domains, respectively; $r_{\mathrm{f}}$ and $r_{\mathrm{m}}$ are the dissolution rates $\left(\mathrm{mol} / \mathrm{L} / \mathrm{s}^{-1}\right)$ normalized to the pore volumes in the fracture and matrix domains, respectively; $l$ is the dimensionless length from the fracture opening to the interior; $t$ is the time (s); $\theta_{\mathrm{f}}$ and $\theta_{\mathrm{m}}$ are the porosities in the fracture and matrix domains, respectively; $\rho_{\mathrm{s}}(\mathrm{kg} / \mathrm{L})$ is the solid density of the sediment; $D\left(\mathrm{~m}^{2} / \mathrm{s}\right)$ is the hydrodynamic dispersion coefficient determined from the Br breakthrough curves (Figure S1 in the Supporting Information); $D_{\mathrm{f}} / \mathrm{L}^{2}{ }_{\mathrm{f}}\left(\mathrm{s}^{-1}\right)$ is the fracture diffusivity normalized to the half-fracture length where both ends of the fracture are open to the advective solution domain; $v(\mathrm{~m} / \mathrm{s})$ is the measured linear pore velocity; $k_{\mathrm{m}}\left(\mathrm{s}^{-1}\right)$ is the mass transfer coefficient between the fracture and matrix; $f_{1}$ is the ratio of the fracture pore volume to the advective pore volume; $f_{2}$ is the ratio of the matrix pore volume to the fracture pore volume.

The boundary and initial conditions for the different domains are given in the Supporting Information. The dissolution rate expression follows that used in Liu et al. (8):

$$
\frac{\partial[\mathrm{U}(\mathrm{VI})]_{\mathrm{aq}}}{\partial t}=k\left[\mathrm{U}(\mathrm{VI})_{\mathrm{solid}}\right]\left[\mathrm{HCO}_{3}^{-}\right]_{\mathrm{tot}}\left(1-I A P / K_{\mathrm{sp}}\right)
$$

The affinity term (IAP/ $\left.K_{\mathrm{sp}}\right)$ was approximated by $[\mathrm{U}(\mathrm{VI})]_{\mathrm{aq}} /$ $[\mathrm{U}(\mathrm{VI})]_{\text {eq }}$ where $\mathrm{U}(\mathrm{VI})_{\mathrm{eq}}$ is the $\mathrm{U}(\mathrm{VI})_{\mathrm{aq}}$ concentration saturated with respect to Na-boltwoodite for a given condition. Note that all other species cancel each other in the affinity term. The value for the dissolution rate constant, $k$, is given in Table 3 and is the same as in Liu et al. (8). The solution compositions used to calculate $\mathrm{U}(\mathrm{VI})_{\mathrm{eq}}$ are composite effluent samples (see the Materials and Methods section) and are listed in Table 2 . $\log K_{\mathrm{sp}}=6.08 \pm 0.5$, was determined by batch experiments $(8)$ with the same sediments used in the present study. This value is higher than, but within the uncertainty of $\log K_{\mathrm{sp}}=5.86 \pm 0.28$ determined by a recent solubility study of Na-boltwoodite (20). The use of the higher value was consistent with the approach of this study, which was to use parameters previously determined by the batch sediment study.

The coupled diffusion, dissolution, and advection model was solved using finite difference and sequential iteration. At each time step, eq 1 was first solved to get $C_{\mathrm{a}}$ in the advective domain. $C_{\mathrm{a}}$ was used to solve eq 2 for $C_{\mathrm{f}}$; and $C_{\mathrm{f}}$ was used to solve eq 3 for $C_{\mathrm{m}}$. Both $C_{\mathrm{f}}$ and $C_{\mathrm{m}}$ were then substituted into eq 6 to determine the dissolution rates in their respective domains. The dissolution rates were used to determine $S_{\mathrm{f}}$ and $S_{\mathrm{m}}$. The $C_{\mathrm{f}}$ was then used to solve $C_{\mathrm{a}}$ again. This process was iterated until convergence.

Comparison of Modeling to Effluent Data. The modeling results are compared to effluent data in Figures 2 and 3. In general, the model simulated the stop-flow (SF) data reasonably well for certain key features, including peak SF $\mathrm{U}(\mathrm{VI})$ aq concentrations, where the simulations tend to match the later SF events more closely than earlier ones. The model does better, for both sediments, when the electrolyte is Ca-DI and the solutions are far below the calculated saturation of Na-boltwoodite. We note that even when the concentrations are not matched in the absolute sense, the simulations do follow the trend in $\mathrm{U}(\mathrm{VI})$ aq for both relative SF peak heights and the regions just after flow has restarted. In detail, the model underpredicted U(VI)aq effluent concentrations during the time of rapidly evolving solution composition, shortly after flow recommenced. Part of this mismatch might be attributed to the unavoidable use of composite solute samples for computing the solubility of Na-boltwoodite. However, as discussed later, this underprediction could reflect other factors.

The model also succeeded in simulating the effect of high $\mathrm{Na}$ and $\mathrm{Na}+\mathrm{Si}$ in the starting SGW2-Na \pm Si electrolytes, where $\mathrm{Na}$ and $\mathrm{Si}$ suppressed the solubility of the uranyl $\mathrm{Na}$-silicate phase, which in turn suppressed local dissolution kinetics and the driving force for diffusion. However, larger deviations between the simulations and effluent SF U(VI)aq concentrations were observed for the $\mathrm{Na} \pm \mathrm{Si}$ enriched groundwaters, where the model tended to underpredict peak $\mathrm{U}(\mathrm{VI}) \mathrm{aq}$. In contrast to the Ca-DI experiments, U(VI) leaching during SF was, in general, solubility limited for these electrolytes; where the SGW2-Na \pm Si SF effluents were mostly near-saturation, given an uncertaintly in $\log K_{\mathrm{sp}}= \pm 0.5$, with respect to the calculated $\mathrm{U}(\mathrm{VI})$ solubility. If the solubility of $\mathrm{U}(\mathrm{VI})$ was underestimated, the simulations would underpredict the concentration of $\mathrm{U}(\mathrm{VI})$ aq either by prematurely slowing the dissolution kinetics (eq. 6) or by simply capping the predicted $\mathrm{U}(\mathrm{VI})$ aq concentration at too low a value. Such an effect would become more manifest for solubility controlled systems. In fact, the model does progressively worse with increases in the calculated saturation index. For example, the model only underpredicts peak SF U(aq) concentrations by $\sim 20-50 \%$ for calculated near-saturated conditions (e.g., column 3: SF2-5 and column 5: SF4-5), but by a factor of $\sim 2-8$ depending on the degree of the calculated supersaturated state.

The model appears to simulate sediment $53 \mathrm{AB}$ better than $61 \mathrm{AB}$. The reason for this is not readily apparent, but we speculate that the microscopic distribution of precipitated $\mathrm{U}(\mathrm{VI})$ may be a factor. Over $95 \%$ of $\mathrm{U}(\mathrm{VI})$ in sediment $53 \mathrm{AB}$ is in domains with high apparent diffusivity, whereas $60 \%$ of $\mathrm{U}(\mathrm{VI})$ in sediment $61 \mathrm{AB}$ is in domains with lower apparent diffusivity (8). Consequently, the diffusion of bulk solution solutes into sediment $61 \mathrm{AB}$ should have been subject to greater mass transfer limitations than for sediment 53AB. Because our model does not treat any solute, except for $\mathrm{U}(\mathrm{VI}) \mathrm{aq}$, as a diffusing species it is possible that the use of effluent compositions to compute the saturation state of $\mathrm{Na}$ boltwoodite in the fracture system is less accurate for sediment $61 \mathrm{AB}$ than for sediment $53 \mathrm{AB}$. If this were the case, then the model should underpredict and overpredict peak SF U(VI)aq effluent concentrations for solubility limited versus not-limited conditions, respectively. This is precisely the case over the last three, and longest duration, SF events for sediment $61 \mathrm{AB}$.

The simulations consistently underpredicted the inter SF advective regime $U(\mathrm{aq})$ concentrations regardless of the sediment and electrolyte; although the match between experimental and model results improved with increasing total reaction time. Could this be due to using under estimated values for the diffusivities or dissolution rate constant that were derived from the batch study? Under estimating $k$ or diffusivity is likely, at least to some extent, due to the unavoidable convolution of dissolution rate and intraparticle diffusion with saturation state in the batch experiments. The column studies would expose just such an issue because fluid flow maintained a low saturation state in the bulk solution. However, because U(VI) release records a coupled dissolution-diffusion process, it is difficult to separate the effects of the individual processes. In this regard, a recent study derived a much higher dissolution rate constant for synthetic Na-boltwoodite (9) than the one obtained in the batch study (8). Errors associated with using a low $k$ should be amplified for the advective regime relative to the SF events.

This study has taken an important step toward addressing the complexities of reactive transport in Hanford sediments 
containing precipitated U(VI). The successes of the model indicated that the approach, which was to construct a model based on microscopic processes and observations that predicts macroscopic observables, is promising and that we have captured key aspects of the physics and geochemistry of the intragrain precipitate system. Divergences between the simulations and column experiments have provided evidence for the need to reevaluate parameters, such as $k$, that were derived from the batch experiments and possibly to consider the diffusion of other key species (e.g., Si, Na, and carbonate). A reparameterization approach that iterates between column and batch, or between column and column, experiments is not likely to yield unique solutions due to the nonlinearity of the coupled dissolution-diffusion process. A better, yet challenging, approach that we are currently undertaking entails independent characterization of key parameters and a more complete description of system geochemistry as a function of time.

\section{Acknowledgments}

This research was primarily supported by the Hanford Tank Farm Vadose Zone Project managed by CH2M HILL Hanford Group, Inc. and funded by the DOE Office of River Protection (ORP). The CH2M HILL Hanford Group, Inc. also collected the contaminated sediments used in this study and supported their initial chemical characterization. Supplementary support was provided by the Department of Energy's Office of Biological and Environmental Research (OBER), Environmental Remediation Sciences Division (ERSD), through their Environmental Remediation Sciences Program (ERSP) to Liu. PNNL is operated for the DOE by Battelle.

\section{Supporting Information Available}

Initial and boundary conditions, and $\mathrm{Br}$ tracer curves. This materials is available free of charge via the Internet at http:// pubs.acs.org.

\section{Literature Cited}

(1) Abdelouas A.; Lutze, W.; Nuttall, H. E. Uranium contamination in the subsurface: characterization and remediation. In Uranium: Mineralogy, Geochemistry and the Environment. Burns, P. C., Finch R. J., Eds.; Mineralogical Society of America: Washington, DC, 1999.

(2) Serne, R. J.; Bjornstad, B. N.; Gee, G. W.; Schaef, H. T.; Lanigen, D. C.; McCain, R. G.; Lindenmeier, C. W.; Orr, R. D.; LeGore, V. L.; Clayton, R. E.; Lindberg, M. J.; Kutnyakov, I. V.; Baum, S. R.; Geiszler, K. N.; Valenta, M. M.; Vickerman, T. S.; Royack, L. J.; Characterization of Vadose zone sediment: Borehole 299-E3346 near tank B-110 in the B-BX-BY waste management area; Pacific Northwest National Laboratory: Richland, WA, 2002.

(3) Dresel, P. E.; Evans, J. C.; Farmer O. T.; Jr., Investigation of Isotopic Signatures for Sources of Groundwater Contamination at the Hanford Site, PNNL-13763; Pacific Northwest National Laboratory: Richland, WA, 2002.

(4) Mckinley, J. P.; Heald S. M.; Zachara, J. M.; Resch, C. T. The identification of uranium bearing phases by X-ray microprobe, electron microprobe, and scanning electron microscopy. In Field Investigation Report for Waste Management Area $B$ - $B X$ - $B Y$, River Protection Project (RPP). RPP-10098; Prepared for the Office of
River Protection by CH2M Hill Hanford Group:Richland, WA, 2002; pp. D122-D129.

(5) Catalano, J. G.; Heald, S. M.; Zachara, J. M.; Brown, G.E.J. Spectroscopic and diffraction study of uranium speciation in contaminated vadose zone sediments from the Hanford site, WA. Environ. Sci. Technol. 2004, 38, 2822-2828.

(6) Wang, Z.; Zachara, J. M.; Gassman, P. L.; Liu, C.; Qafoku, O.; Catalano, J. G. Fluorescence spectroscopy of U(VI)-silicates and U(VI)-contaminated Hanford sediment. Geochim. Cosmochim. Acta 2005, 69, 1391-1403.

(7) Mckinley, J. P.; Zachara, J. M.; Liu, C.; Heald, S. M.; Prenitzer, B. I.; Kempshall, B. W. Microscale controls on the fate of contaminant uranium in the vadose zone, Hanford Site, WA. Geochim. et Cosmochim, Acta 2006, 70, 1873-1887.

(8) Liu, C.; Zachara, J. M.; Qafoku, O. S.; McKinley, J. P.; Heald, S. M.; Wang, Z. Dissolution of uranyl microprecipitates in subsurface sediments at Hanford Site, WA. Geochim. Cosmochim. Acta 2004, 68, 4519-4537.

(9) Liu, C.; Zachara, J. M.; Yantasee, W.; Majors, P. D.; McKinley, J. P. Microscopic reactive diffusion of uranium in the contaminated sediments at the Hanford site, USA: Characterization and modeling. Water Resour. Res. 2006, 42, W12420.

(10) Olander, D. R.; Eyal, Y. Leaching of uranium and thorium from monazite: II. elemental leaching. Geochim. Cosmochim. Acta 1990, 54, 1879-1887.

(11) Reeder, R. J.; Elzinga, E. J.; Tait, K. D.; Rector, K. D.; Donohoe, R. J.; Morris, D. E. Site-specific incorportation of uranyl carbonate species at the calcite surface. Geochim. Cosmochim. Acta 2004, 68, 4799-4808.

(12) Giammar, D. E.; Hering, J. G. Time scales for sorption-desorption and surface precipitation of uranyl on goethite. Environ. Sci. Technol. 2002, 35, 3332-3337.

(13) Braithewaite, A.; Livens, F. R.; Richardson, S.; Howe, M. T. Kinetically released uranium from soils. Eur. J. Soil Sci. 1997, 48, 661-673.

(14) Mason, C. F.; Turney, W. R.; Thomson, B. M.; Lu, N.; Longmire, P. A.; Chisholm-Brause, C. J. Carbonate leaching of uranium from contaminated soils. Environ. Sci. Technol. 1997, 31, 27072711.

(15) Qafoku, N. P.; Zachara, J. M.; Liu, C.; Gassman, P. L.; Qafoku, O.; Smith, S. C. Kinetic desorption and sorption of U(VI) during reactive transport in contaminated Hanford sediments. Environ. Sci. Technol. 2005, 39, 3157-3165.

(16) Rogers, P. M., Site-Specific SST Phase 1 RFI/CMS Work Plan Addendum for WMA B-BX-BY, RPP-6072; CH2M Hill Hanford Group,: Richland, WA, 2000.

(17) Allison, J. D.; Brown, D. S.; Novo-Gradac, K. J. MINTEQA2/ PRODEFA2, A GeochemicalAssessment Model for Environmental Systems: User Manual Supplement for Version 4.0; U.S.; Environmental Protection Agency: Washington, DC, 1998.

(18) Rai, D.; Felmy, A. R.; Hess, N. J.; Moore, D. A.; Yui, M. A. Thermodynamic model for the solubility of $\mathrm{UO}_{2}(\mathrm{am})$ in the aqueous $\mathrm{K}^{+}-\mathrm{Na}^{+}-\mathrm{HCO}_{3}{ }^{-}-\mathrm{CO}_{3}{ }^{2-}-\mathrm{OH}^{-}-\mathrm{H}_{2} \mathrm{O}$ system. Radiochim. Acta 1998, 82, 17-25.

(19) Guillaumont, R.; Fanghanel, T.; Neck, V.; Fuger, J.; Palmer, D. A.; Grenthe, I.; Rand, M. H. Update on the Chemical Thermodynamics of Uranium, Neptunium, Plutonium, Americium, and Technetium; Elsevier B. V.: Amsterdam, 2003.

(20) Ilton, E. S.; Liu, C.; Yantasee, W.; Wang, Z.; Moore, D. A.; Felmy, A. R.; Zachara, J. M. The dissolution of synthetic Na-boltwoodite in sodium carbonate solutions. Geochim. Cosmochim. Acta 2006, 70, 4836-4849.

(21) Toride, N.; Liej, F. J.; van Genuchten, M. T. The CXTFIT Code for Estimating Transport Parameters from Laboratory or Field Tracer Experiments; U.S. Salinity Laboratory: Beltsville, MD, 1999.

ES071113M 